Filo. y Lingüi.7(1 y 2): 117-120,1981.

PARADOJA, METAFORA Y SIMBOLO EN

“DEBIL DEL ALBA" DE PABLO NERUDA

Emilia Macaya Trejos *

\section{EL POEMA}

\section{“DEBiL DEL ALBA"}

El día de los desventurados, el día pálido se asoma con su desgarrador olor frío, con sus fuerzas en gris, sin cascabeles, goteando el alba por todas partes: es un naufragio en el vacío, con un alrededor de llanto.

Porque se fue de tantos sitios la sombra húmeda, callada, de tantas cavilaciones en vano, de tantos parajes terrestres en donde debió ocupar hasta el designio de las raices, de tanta forma aguda que se defendía.

Yo lloro en medio de lo invadido, entre lo confuso, entre el sabor creciente, poniendo el oído en la pura circulación, en el aumento, cediendo sin rumbo el paso a lo que arriba, a lo que surge vestido de cadenas y claveles, yo sueño, sobrellevando mis vestigios morales.

Nada hay de precipitado, ni de alegre, ni de forma orgullosa, todo aparece haciéndose con evidente pobreza, la luz de la tierra sale de sus párpados no como la campanada, sino más bien como las lágrimas:

el tejido del día, su lienzo débil, sirve para una venda de enfermos, sirve para hacer señas en una despedida, detrás de la ausencia: es el color que sólo quiere reemplazar, cubrir, tragar, vencer, hacer distancias.

Estoy solo entre materias desvencijadas, la lluvia cae sobre mi, y se me parece, se me parece con su desvario, solitaria en el mundo muerto, rechazada al caer, y sin forma obstinada.

* Costarricense. Profesora de Literatura Clásica y Española en la Escuela de Filología, Facultad de Letras, Universidad de Costa Rica.
Muchas cosas han sido señaladas en torno al poema "Débil del alba", de Pablo Neruda. Sin embargo, es al partir de una posible justificación dialéctica de la metáfora como la figura encargada de realizar la superación de los contrarios, cuando se observa no sólo lo que podría determinarse como la dinámica de base dentro del poema mencionado, sino también la raíz que justificaría el lugar de privilegio ocupado por lo metafórico, en relación con las demás figuras del lenguaje.

Es indudable, dentro de la crítica literaria actual, la preocupación profunda que causa el problema de la metáfora; los estudios de Ricoeur o de Le Guern, entre otros, así lo testimonian. Sin embargo, creemos que la justificación de esa figura privilegiada a partir de una visión dialéctica permitiría concebirla, en su carácter de síntesis, como el procedimiento poético por excelencia-razón de su eficacia e importancia- además de que explicaría, en la unidad de una misma visión, mucho de lo que, con otras palabras, se ha dicho sobre ella en tantas oportunidades.

Si se observa el estudio de Le Guern (1) se percibe que a partir de la noción de sema, en un nivel infralingüístico, la metáfora como sustitución de un término por otro encuentra su fundamento en una modificación efectuada sobre la colección de los semas nucleares; dicho en otros términos, añadiendo o suprimiendo semas sobre una base que permanece sin alteraciones, se establece, a partir de aquello que tienen en común elementos aparentemente distintos, una figura que encontrará lo conjuntivo en lo opuesto: ésta es la metáfora.

En Jean Cohen (2) y gracias a ese elemento de soporte que es la concepción de "figura" como desvío en el uso común del lenguaje, la metáfora queda definida según el procedimiento por el cual, el cambio de sentido en una de las palabras acarrea la reducción de tal desvío, a fin de reconstruir, en un nivel superior, el código de pertinencia que rige los significados. Se trata, por tanto, de una especie de ruptura semántica producida en el lenguaje común, la cual se supera en virtud de una síntesis 
lograda en el nivel superior del lenguaje poético; la discordancia en la esfera de lo denotativo se supera, pues, gracias a la unidad recuperada en el ámbito de lo connotativo. A esa síntesis, a esa unidad retomada en un plano superior, es a lo que se llama metáfora.

Hay, en efecto, muchos puntos de coincidencia entre las diferentes concepciones referidas a la figura metafórica, si se trata de buscar la $\backsim$ xplicación a la luz de un planteamiento dialéctico del problema. Tal planteamiento facilitaría, por ejemplo, el afán de Ricoeur (3) en el sentido de proyectar el efecto metafórico a todo el discurso, y no sólo a unos cuantos términos del mismo. Es más, una vez fundamentada la metáfora según su carácter de síntesis, es posible, y quizás hasta forzoso, extender las justificaciones a otras dos figuras que guardan con ello, a no dudarlo, un parentesco innegable: la paradoja y el símbolo.

La paradoja es la oposición hecha evidencia, a partir de dos opuestos que subsisten en cuanto tales sin posibilidad de superación, a no ser que se transformen en otra figura diferente. Vista así, la paradoja sería entonces lo que bien podría llamarse una pre-metáfora, y su superación -valga decir, la obtención de la síntesis - remitiría por tanto al ámbito de lo metafórico. Finalmente, en un nivel de abstracción aún mayor, el símbolo concentraría, como hipermetáfora, una multiplicidad de oposiciones y de resoluciones, de contrarios sintetizados, en función de una significación más general, plurívoca y totalizante. El símbolo, como figura compleja, abarcadora, encerraría, dentro de la estructura de lo literario poético, toda la dinámica del juego dialéctico, sin que esto quiera decir, por supuesto, que ese símbolo pierda su poder de transformarse en el contrario de una nueva paradoja. Antes bien, y visto de tal manera, lo simbólico sería, precisamente por su carácter de figura capaz de concentrar un vastísimo juego significativo, uno de los puntos de apoyo más sólidos para trascender lo puramente poético, en función del establecimiento de relaciones con elementos presentes más allá del poema, ya sean éstos de índole sociológica, filosófica, histórica o psicológica.

Pues bien: si a través de la presencia de la paradoja como manifestación de los contrarios, de la metáfora como superación en virtud de la síntesis, y del símbolo como lo pluri-metafórico, yo hago evidente, en un poema dado, toda la mecánica que motiva ese dinamismo, no sólo le imprimo a tal creación concreta un máximo de movimiento, de vida, sino que traslado esas figuras sintéticas - por su carácter mismo de superacióna los más altos niveles de expresión poética, dotación de sentido $y$, por lo tanto, de valor creativo. Es propósito de este trabajo, así, demostrar que todo esto que ha sido señalado, es precisamente lo que se yergue como pauta básicá de construcción dentro del poema "Débil del alba", de Pablo Neruda, razón que explicaría, a nuestro juicio, su inmensa fuerza significativa $y$ creadora.

Desde el título mismo, "Débil del alba", se introduce al lector implícito en un juego poético donde lo consabido va a establecer una aparente vía de acceso al poema, la cual, al resultar finalmente invertida, se transforma en vehículo para una comprensión opuesta; así, se crea la paradoja.

Para enunciar con detalle lo afirmado, puede hacerse la siguiente consideración: "Débil del alba" parte de una imagen del amanecer que, aparentemente, pretende dotar de cierto sentido general a la composición. Esta primera imagen genera una oposición fundamental -en nada ajena aún a lo que podría considerarse como lógico dentro de la visión del momento del albaformada a partir de los opuestos luz $\leftrightarrow$ sombra.Sin embargo -y aquí comienza el juego- el mundo que surge en virtud de la luminosidad inicial, es un mundo carente de sentido, un mundo en desintegración, por lo cual, la luz que lo ilumina se transforma, por inversión situacional, en lo negativo, en lo aniquilante; la imagen tradicional del amanecer, concebido como luminosidad, como vida reiniciada, queda entonces destruida. Son las sombras, por el contrario, las que al ocultar esa absurda creación, caótica y contradictoria, pasan a conformar la esfera de lo positivo, al marcar la única vía de salvación posible: el ocultamiento de lo existente. Se forma así la primera gran paradoja, en virtud de un amanecer transformado en ansia de oscuridad, en negación, naufragio y destrucción.

"El día de los desventurados, el día pálido se asoma / con un desgarrador olor frío, con sus fuerzas en gris, / sin cascabeles, goteando el alba por todas partes: / es un naufragio en el vacío, con un alrededor de llanto".

La presencia del yo poético resulta igualmente llamativa, no sólo porque refuerza, a través de un proceso de identificación, la desintegración de lo creado, sino también porque conforma una paradoja más. El yo va asumiendo, paulatinamente, todas las propiedades de ese mundo que la 
sombra debe ocultar, hasta que, ya en la última estrofa, la lluvia que cae sobre ambos se encarga de fusionarlos, de hermanarlos en el abandono y en el naufragio.

\footnotetext{
"Estoy solo entre materias desvencijadas, lh lluvia cae sobre mí, y se me parece, se me parece con su desvarío, solitaria en el mundo muerto, rechazada al caer, y sin forma obstinada".
}

Ese hablante lírico, que se acentúa como sujeto poético, se yergue a la vez, en una nueva contradicción, como autonegación, como conciencia que se afirma para aniquilarse, de la misma manera en que la lluvia, por excelencia elemento mítico de fecundación terrestre, resulta "rechazada al caer", en un intento agotado dentro de su propio absurdo.

Según lo dicho hasta el momento, es lícito pensar que un análisis del código de sensaciones presente en el poema -el cual es necesario considerar por el peso que tiene la sinestesia en el conjunto de las figuras que lo componen- obligaría a asumir como predominante la sensación visual, en función de la doble vía de lo luminoso y lo obscuro, conformados como opuestos. En efecto, esto es así. Sin embargo, y ya al final de la quinta estrofa, la visualidad no es simplemente luz, sombra o cromatismo indeterminado, sino que es color que cubre, traga, vence, lo cual parece remitir al negro - producto de la absorción total de la luz - de donde el día, al quedar asociado de manera plena a la negrura, pasaría a consolidar una nueva figura paradójica: la de "oscura claridad", la de "negra luminosidad". El alba, por tanto, en lugar de construir el mundo, de conformarlo en su luz, lo destruye, lo aniquila en su sombra.

Una mirada a los lexemas comprendidos en la composición de Neruda que nos ocupa, reforzaría lo afirmado hasta ahora; en su mayor parte, remiten a pesimismo, desventura, sinsentido, silencio, soledad, destrucción, muerte. Si tuviera que hablarse de tono en el poema, debería señalarse como lúgubre; $\mathrm{y}$ si fuese necesario asociar el vocabulario al color, habría de realizarse esto en función de la "negrura léxica", lo que parecería enfatizar la paradoja del "negro día", mencionada líneas atrás. Es más, si a la visión del léxico se suma la de la sintaxis, los resultados se tornan aún más reveladores. Una mirada a los complementos circunstanciales -que lógicamente y por lo dicho hasta ahora, en efecto abundan- obligan a considerar como actitudes básicas el pesimismo y el sinsentido, como sensaciones primarias el frío y la sombra, como consecuencias ineludibles, el aniquilamiento y la muerte. Sin embargo, es al determinar los sujetos de cada estrofa cuando se comprueba la solidez con que el poema ha sido construido, ya que esos sujetos no sólo concentran los grandes temas que han sido puestos en juego, sino que muestran, a la vez, una progresión que los relaciona de manera altamente significativa.

Obsérvese el siguiente cuadro:

\begin{tabular}{|ll|}
\hline ESTROFAS & \multicolumn{2}{|l|}{ SUJETOS } \\
\hline I & DIA \\
\hline II & SOMBRA \\
\hline III & YO \\
\hline IV & NADA \\
\hline V & MUERTE \\
\hline VI & YO \\
\hline
\end{tabular}

Las dos primeras estrofas encierran la paradoja luz $\leftrightarrow$ sombra.

La tercera estrofa y la última -partes media y final del poema - se centran en el YO. Las estrofas cuarta y quinta, remiten a identificación, a conjunción, en virtud de los términos "muerte" y "nada" que resultan, así, hermanados.

Es nuestra opinión que ese juego de los sujetos concentra lo que se ha señalado como la dinámica de base en todo el poema: enfrentar a través de la paradoja, para sintetizar a partir de la metáfora. Y así, una vez examinada la composición de Neruda a partir de las paradojas presentes, se torna problema de primer orden el establecimiento del plano metafórico que habrá de reunirlas. En este sentido, una lectura de "Débil del alba" dentro de un nivel más abarcador, permitiría hablar del poema como metáfora del nacimiento: hay en efecto un esfuerzo desde el interior que es "húmedo", que es "callado", que es "oscuro", que es "designio de raíces", hacia el "ceder sin rumbo el paso a lo que arriba", tránsito que se da en medio del lamento, de ese llanto primigenio que arroja a un mundo concebido - he aquí lo más importante - como inhóspito, absurdo y en eviden- 
te desintegración. Se presenta, por lo tanto, una conjunción de elementos, que permite reunir los términos "amanecer" y "nacimiento" en una comparación o, mejor todavía, en una síntesis metafórica proyectada, como pediría Ricoeur, sobre la composición entera. Más aún - $v$ siemnnre en busca de esa unidad mayor, de esa hiper-metáfora que sería el símbolc. - habría de hallarse una síntesis final, solución de todas las contradicciones y reunión de todas las metáforas, en esa idea de la condición humana que daría sentido a todo el poema, a partir de una definición del "nacer" comprendido como el "comenzar a morir".

\section{NOTAS}

(1) Michel Le Guern. Metáfora y Metonimia Madrid, Cátedra, 1978.

(2) Jean Cohen. Estructura del lenguaje poético. Madrid, Gredos, 1970.

(3) Paul Ricoeur. La metáfora viva. Buenos Aires, Ed. Megápolis, 1977.

\section{BIBLIOGRAFIA}

Barthes, Roland y otros. Estructuralismo y literatura. Buenos Aires, Ed. Nueva Visión, 1972.

Cohen, Jean. Estructura del lenguaje poético. Madrid, Gredos, 1970.
La determinación misma de la paradoja como razón de la existencia humana hablaría entonces, paradójicamente también, de un sentido para esa existencia, de una justificación para la raza humana entera. En el reconocimiento de la contradicción está nuestra grandeza y ella hablaría, así, de la gran síntesis. El poema en su totalidad, como símbolo de esa condición del hombre, reuniría y otorgaría significación abarcadora a todas las paradojas, a todas las metáforas, cuya dinámica, a la vez, habrá dado fundamento artístico de existencia, a todo el conjunto poemático.

Greimas, A. J. y otros. Ensayos de semiótica poética. Barcelona, Ed. Planeta, 1976.

Le Guern, Michel. Metáfora y metonimia. Madrid, Cátedra, 1978.

Neruda, Pablo. Obras completas. Buenos Aires, Losada, 1973.

Ricoeur, Paul. La metáfora viva. Buenos Aires, Ed. Megápolis, 1977.

Riffaterre, Michaele. Ensayos de estilistica estructural. Barcelona, Seix Barral, 1975.

Talens, J.y otros. Elementos para una semiótica del texto artístico. Madrid, Cátedra, 1978. 